\title{
三個のサイリスタと一個の共振スイッチから成る三相正弦波整流器
}

\author{
正 員 伊藤 良三* 正 員 石坂 耕一*
}

\section{Three-Phase Sinusoidal Rectifier Consisting of Three Thyristors and a Resonant Switch}

\author{
Ryozo Itoh*, Member, Kouichi Ishizaka*, Member
}

Three-phase sinusoidal rectifier consisting of three thyristors and a resonant switch is presented. The switching transition of resonant switch is mainly governed by a series resonance and this allows the thyristors to turn on and off under the zero-current switching condition. Also, the currents flowing through power devices are always limited to the dc current. The experimental prototype employing three inverter-grade thyristors and two insulated-gate bipolar transistors is implemented to investigate the operation. The results confirm that the sinusoidal input currents with a near-unity power factor can be obtained under the pulse-width modulation.

キーワード：三相整流器, サイリスタ, 共振スイッチ, ソフトスイッチング, パルス幅変調, 正弦波入力電流

Keywords: three-phase rectifier, thyristors, resonant switch, soft-switching, pulse-width modulation, sinusoidal input currents

\section{1. まえがき}

直流側に電流平滑用インダクタを有する三相整流器は, 三個の自己消弧形素子を用いて実現でき，パルス幅変調の 適用も可能である ${ }^{(1)}$ 。本レターは, 数 $\mathrm{kW}$ 程度のインバー タ用ソフトスイッチング正弦波整流器を得るために, 文献 (1)の自己消弧形素子をサイリス夕に置換すると共に，ロス レススナバの機能を併せ持つ共振スイッチ(2)を直流回路に 挿入した回路構成を提案したものであり，パルス幅変調時 の実験から，入力電流を高力率で正弦波状に制御できるこ とを明らかにする。

\section{2. 主回路構成と動作原理}

提案する三相整流器を図 1 に示す。ただし， L と C, $\mathrm{L}_{\mathrm{d}}$ と $\mathrm{C}_{\mathrm{d}}$ は，それぞれ，交流回路および直流回路における低 域通過フィルタを構成する。また， $\mathrm{D}_{\mathrm{f}}$ は環流ダイオードで あり，サイリスタ，ダイオードのターンオン・ターンオフ は，インダクタ $\mathrm{L}_{\mathrm{r}}$, キャパシタ $\mathrm{C}_{\mathrm{r}}, \mathrm{IGBT}$ で示す自己消弧 形素子 $\mathrm{Q}_{\mathrm{r} 1}, \mathrm{Q}_{\mathrm{r} 2}$ およびダイオード $\mathrm{D}_{\mathrm{r} 1}, \mathrm{D}_{\mathrm{r} 2}$ から成る共振ス イッチ (2) の動作に大きく依存する。なお，参考のため，共 振スイッチが無く, サイリスタのみで通常の位相制御を行 わせるとき，制御遅れ角は $0 \sim \pi / 3$ に限定される。図 2 は， 本レターで適用するパルス幅変調法を $\mathrm{v}_{\mathrm{u}} \geq 0, \mathrm{v}_{\mathrm{v}} \geq 0$ かつ $\mathrm{v}_{\mathrm{w}}<0$ が成立する $\pi / 3$ の範囲で示したものである。困中， $\mathrm{e}_{\mathrm{mu}}, \mathrm{e}_{\mathrm{mv}}$ はそれぞれ $\mathrm{v}_{\mathrm{u}}, \mathrm{v}_{\mathrm{v}}$ と同位相の正弦波変調波であ り, 変調率 $\mathrm{M}$ は三角波搬送波 $\mathrm{e}_{\mathrm{cu}}, \mathrm{e}_{\mathrm{cv}}$ の大きさに対する変

\footnotetext{
*福岡大学

干 814-0180 福岡市城南区七隈 8-19-1

Fukuoka University

8-19-1, Nanakuma, Jonan-ku, Fukuoka 814-0180
}

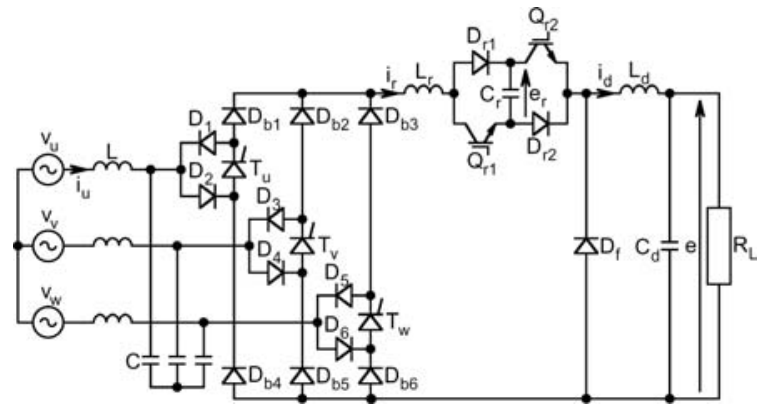

図 1 提案する三相正弦波整流器

Fig. 1. Proposed three-phase sinusoidal rectifier.

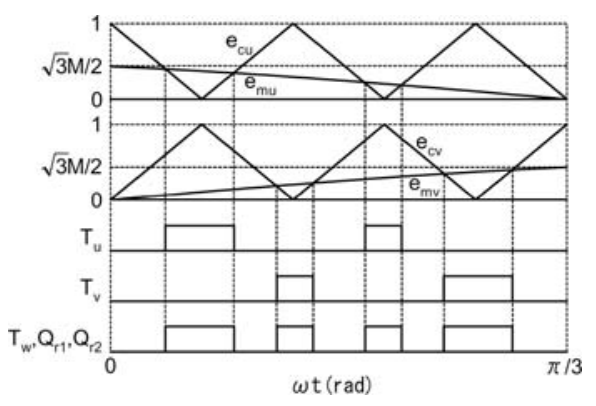

図 2 パルス幅変調法

Fig. 2. Pulse-width modulation scheme.

調波の大きさの比で定義される。図 2 の $\mathrm{e}_{\mathrm{cu}}$ のピーク間で $\mathrm{Q}_{\mathrm{r} 1}, \mathrm{Q}_{\mathrm{r} 2}, \mathrm{~T}_{\mathrm{u}}, \mathrm{T}_{\mathrm{w}}$ のオンゲート信号 $\mathrm{v}_{\mathrm{g}}$ を印加, 遮断した 場合の動作モードは， $\mathrm{v}_{\mathrm{u}}>\mathrm{v}_{\mathrm{v}}$ のとき図 3 のように表され る。ただし，簡単のため，交流側低域通過フィル夕は無視 し, $\mathrm{e}_{\mathrm{cu}}$ の一周期 $\mathrm{T}$ の間, $\mathrm{v}_{\mathrm{uw}}$ は一定, $\mathrm{i}_{\mathrm{d}}$ はその平均值 $\mathrm{I}_{\mathrm{d}}$ に 


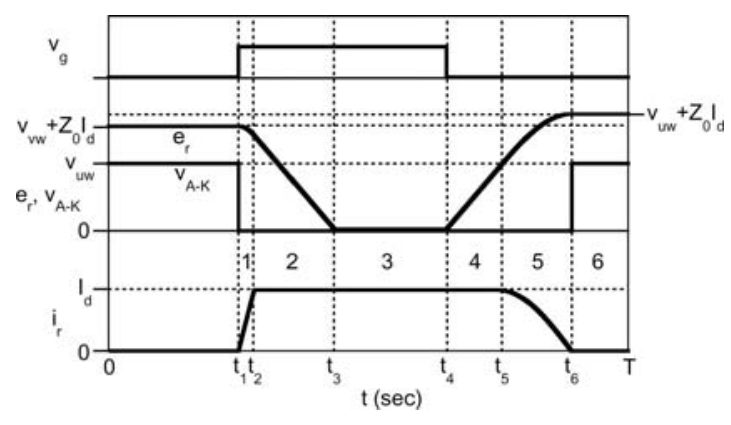

図 3 動作モード波形

Fig. 3. Waveforms illustrating modes of operation.

等しいと仮定している。また，サイリス夕に直接接続され たダイオードのターンオン・ターンオフ動作はサイリスタ のそれと同じであるので記述を省略する。なお， $\mathrm{v}_{\mathrm{A}-\mathrm{K}}$ はサ イリスタ $\mathrm{T}_{\mathrm{u}}$ のアノード・カソード間電圧を示し， $\mathrm{T}_{\mathrm{u}}$ に流 れる $\mathrm{u}$ 相電流 $\mathrm{i}_{\mathrm{u}}$ はインダク夕電流 $\mathrm{i}_{\mathrm{r}}$ に等しい。さらに, $\mathrm{Z}_{0}$ は共振回路の特性インピーダンスであり, $\mathrm{Z}_{0}=\left(\mathrm{L}_{\mathrm{r}} / \mathrm{C}_{\mathrm{r}}\right)^{1 / 2}$ で 与えられる。以下, $\mathrm{Q}_{\mathrm{r} 1}, \mathrm{Q}_{\mathrm{r} 2}, \mathrm{~T}_{\mathrm{u}}, \mathrm{T}_{\mathrm{w}}$ にオンゲート信号が 印加されるまで， $\mathrm{I}_{\mathrm{d}}$ は $\mathrm{D}_{\mathrm{f}}$ を通って環流し，0〜 $\mathrm{t}_{1}$ に示すよ うに $\mathrm{e}_{\mathrm{r}}=\mathrm{v}_{\mathrm{vw}}+\mathrm{Z}_{0} \mathrm{I}_{\mathrm{d}}>\mathrm{v}_{\mathrm{uw}}, \mathrm{i}_{\mathrm{r}}=0$ が成立しているとして, 図 3 の動作モードの概略を説明する。

(1) $\mathrm{t}_{1}$ でオンゲート信号 $\mathrm{v}_{\mathrm{g}}$ が印加されたとき，それま で $\mathrm{i}_{\mathrm{r}}=0$ であったので, $\mathrm{Q}_{\mathrm{r} 1}, \mathrm{Q}_{\mathrm{r} 2}, \mathrm{~T}_{\mathrm{u}}, \mathrm{T}_{\mathrm{w}}$ が ZCS で夕ー ンオンし, $\mathrm{D}_{\mathrm{b} 6}-\mathrm{T}_{\mathrm{w}}-\mathrm{D}_{5}-\mathrm{v}_{\mathrm{w}}-\mathrm{v}_{\mathrm{u}}-\mathrm{D}_{2}-\mathrm{T}_{\mathrm{u}}-\mathrm{D}_{\mathrm{b} 1}-\mathrm{L}_{\mathrm{r}}-\mathrm{Q}_{\mathrm{r} 1}-\mathrm{C}_{\mathrm{r}}-\mathrm{Q}_{\mathrm{r} 2}-\mathrm{D}_{\mathrm{f}}$ の共振回路で $\mathrm{i}_{\mathrm{r}}$ が増加しながら $\mathrm{C}_{\mathrm{r}}$ を放電する。(2) $\mathrm{i}_{\mathrm{r}}$ が $\mathrm{t}_{2}$ で $\mathrm{I}_{\mathrm{d}}$ に達すると， $\mathrm{D}_{\mathrm{f}}$ に流机る電流が 0 になるため, $\mathrm{D}_{\mathrm{f}}$ は ZCS でターンオフし， $\mathrm{C}_{\mathrm{r}}$ は $\mathrm{I}_{\mathrm{d}}$ によって直線的に放電を続 ける。(3) $\mathrm{e}_{\mathrm{r}}$ が $\mathrm{t}_{3}$ で 0 まで低下すると， $\mathrm{D}_{\mathrm{r} 1}, \mathrm{D}_{\mathrm{r} 2}$ は，各々 の端子電圧が 0 であることから, ZVS でターンオンし， $\mathrm{i}_{\mathrm{r}}$ $=\mathrm{I}_{\mathrm{d}}$ は $\mathrm{Q}_{\mathrm{r} 1}-\mathrm{D}_{\mathrm{r} 2}$ と $\mathrm{D}_{\mathrm{r} 1}-\mathrm{Q}_{\mathrm{r} 2}$ の枝に分流する。また， $\mathrm{e}_{\mathrm{r}}$ は 0 の状態が維持される。( 4 ) パルス幅変調法で決まる $\mathrm{t}_{4}$ で $\mathrm{v}_{\mathrm{g}}$ が遮断されたとき， $\mathrm{t}_{4}$ まで $\mathrm{e}_{\mathrm{r}}=0$ であったので， $\mathrm{Q}_{\mathrm{r} 1}, \mathrm{Q}_{\mathrm{r} 2}$ はZVS でターンオフする。 $\mathrm{t}_{4}$ の後, $\mathrm{i}_{\mathrm{r}}=\mathrm{I}_{\mathrm{d}}$ が $\mathrm{D}_{\mathrm{r} 1}-\mathrm{C}_{\mathrm{r}}-\mathrm{D}_{\mathrm{r} 2}$ を 通って流れ， $\mathrm{C}_{\mathrm{r}}$ は直線的に充電される。(5) $\mathrm{e}_{\mathrm{r}}$ が上昇して $\mathrm{t}_{5}$ で $\mathrm{v}_{\mathrm{uw}}$ に達すると， $\mathrm{i}_{\mathrm{r}}$ が減少し始めるので， $\mathrm{D}_{\mathrm{f}}$ が ZCS でターンオンし, $\mathrm{D}_{\mathrm{b} 6}-\mathrm{T}_{\mathrm{w}}-\mathrm{D}_{5}-\mathrm{v}_{\mathrm{w}}-\mathrm{v}_{\mathrm{u}}-\mathrm{D}_{2}-\mathrm{T}_{\mathrm{u}}-\mathrm{D}_{\mathrm{b} 1}-\mathrm{L}_{\mathrm{r}}-\mathrm{D}_{\mathrm{r} 1}-\mathrm{C}_{\mathrm{r}}-$ $\mathrm{D}_{\mathrm{r} 2}-\mathrm{D}_{\mathrm{f}}$ の共振回路で $\mathrm{C}_{\mathrm{r}}$ の充電が継続される。(6) $\mathrm{e}_{\mathrm{r}}$ が最 大值 $\mathrm{v}_{\mathrm{uw}}+\mathrm{Z}_{0} \mathrm{I}_{\mathrm{d}}$ まで上昇すると， $\mathrm{i}_{\mathrm{r}}$ が 0 になるため， $\mathrm{T}_{\mathrm{u}}$, $\mathrm{T}_{\mathrm{w}}$ は $\mathrm{ZCS}$ でターンオフし, 次に $\mathrm{Q}_{\mathrm{r} 1}, \mathrm{Q}_{\mathrm{r} 2}, \mathrm{~T}_{\mathrm{v}}, \mathrm{T}_{\mathrm{w}}$ にオ ンゲート信号が印加されるまで, $\mathrm{i}_{\mathrm{r}}=0, \mathrm{e}_{\mathrm{r}}=\mathrm{v}_{\mathrm{uw}}+\mathrm{Z}_{0} \mathrm{I}_{\mathrm{d}}$ で ある。この状態は， $\mathrm{e}_{\mathrm{r}}$ の值を除き， $\mathrm{Q}_{\mathrm{r} 1}, \mathrm{Q}_{\mathrm{r} 2}, \mathrm{~T}_{\mathrm{u}}, \mathrm{T}_{\mathrm{w}}$ に才 ンゲート信号が印加される前の状態に等しい。

以上の説明から，全半導体素子はソフトスイッチングで ターンオン・ターンオフし，素子に流れる電流は $\mathrm{I}_{\mathrm{d}}$ を上ま わることはない。また，図 3 から, $\mathrm{i}_{\mathrm{r}}$ の導通時間はオンゲー 卜信号 $\mathrm{v}_{\mathrm{g}}$ より $\mathrm{t}_{6}-\mathrm{t}_{4}$ だけ長くなるが， $\mathrm{L}_{\mathrm{r}}, \mathrm{C}_{\mathrm{r}}$ の值が小さい ときには， $\mathrm{t}_{6}-\mathrm{t}_{4}$ も小さい。したがって， $\mathrm{v}_{\mathrm{g}}$ と $\mathrm{i}_{\mathrm{r}}$ の相違が入 力電流波形へ大きな影響を及ぼすとは考えられず，図 2 の パルス幅変調法に従った入力電流の正弦波化が期待できる。

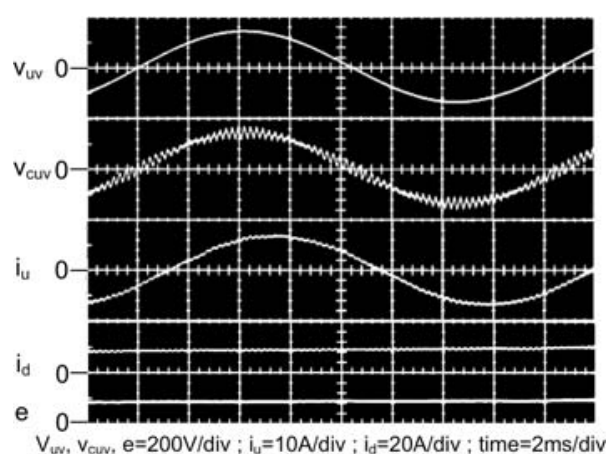

図 4 実測動作波形

Fig. 4. Experimental operating waveforms.

\section{3. 実験結果}

本レターでは, 回路定数を $\mathrm{L}=2.123 \mathrm{mH}, \mathrm{C}=20 \mu \mathrm{F}$, $\mathrm{L}_{\mathrm{r}}=8.3 \mu \mathrm{H}, \mathrm{C}_{\mathrm{r}}=0.1 \mu \mathrm{F}, \mathrm{L}_{\mathrm{d}}=11.30 \mathrm{mH}, \mathrm{C}_{\mathrm{d}}=2000 \mu \mathrm{F}$, $\mathrm{R}_{\mathrm{L}}=9.41 \Omega$ とし, 電源線間電圧㧍よび搬送波周波数を各々 $100 \mathrm{~V}(60 \mathrm{~Hz}) ， 4.14 \mathrm{kHz}$ に設定して実験を行った。なお， $\mathrm{T}_{\mathrm{u}} \sim \mathrm{T}_{\mathrm{w}}$ にはターンオフ時間が $15 \mu \mathrm{s}$ の高速サイリスタを用 いた。図 4 は， $\mathrm{M}=0.8$ のときの実測動作波形を示し, 入力 電流の実効值抢よび出力電圧の平均值は，それぞれ $4.78 \mathrm{~A}$, $83.2 \mathrm{~V}$ である。ただし， $\mathrm{v}_{\mathrm{cuv}}$ は交流側キャパシタの uv 相 間の電圧を示す。図より，入力電流 $\mathrm{i}_{\mathrm{u}}$ は，ほとんど力率 1 で正弦波状に制御されていることがわかる。ちなみに，入 力電流歪みの主な原因となる低次高調波の基本波に対する 割合は, FFT アナライザによる実測から, 第 5 次, 7 次, 11 次，13 次など総て $1 \%$ 未満に抑制されており，実測総合歪 み率（THD）は 1.334\%，実測総合力率は 0.999 であった。 一方, 図 1 の整流器は半導体素子数が多いため, 文献 (1)の 整流器と比較して, 電力変換効率の改善はそれほど期待で きないが，オン・オフに伴うリンギングは全素子で観測さ れなかった。

4. あとがき

以上，三個のサイリスタと一個の共振スイッチから成る 三相整流器を提案し，パルス幅変調時の実験から，入力電 流をほとんど力率 1 で正弦波状に制御できることを示した。 今後，シミュレーションによる回路動作の詳細な検証を行 う予定である。最後に，本研究の装置作成および実験に協 力された福岡大学大学院博士課程前期学生中山陽介君に紙 面を借りて深謝する。

(平成 18 年 11 月 8 日受付，平成 19 年 3 月 9 日再受付)

$$
\text { 文献 }
$$

(1) L. Malesani and P. Tenti: "Three-Phase AC/DC PWM Converter with Sinusoidal AC Currents and Minimum Filter Requirements", IEEE Trans. IA., 23, 1, pp.71-77 (1987-1/2)

(2) N. Kimura, T. Morizane, and K. Taniguchi: "Analysis of PFC Boost Converter with Soft-Switching Configuration", T. IEE Japan, Vol. 119-D, No.5, pp.617-627 (1999-5) (in Japanese)

木村紀之・森實俊充・谷口勝則：「ソフトスイッチング単相昇圧形 力率改善コンバータの特性解析と高調波抑制」, 電学論 $\mathrm{D}, \mathbf{1 1 9}, 5$, pp.617-627 (1999-5) 